\title{
Expression, Purification, and Characterization of \\ Human Cystatin C Monomers and Oligomers
}

\author{
Tyler J. Perlenfein and Regina M. Murphy \\ Department of Chemical and Biological Engineering \\ 1415 Engineering Drive \\ Madison, WI 53706 \\ University of Wisconsin-Madison
}

Corresponding author: Regina M. Murphy, regina.murphy@wisc.edu 


\begin{abstract}
Human cystatin $\mathrm{C}$ (cysC) is a soluble basic protein belonging to the cysteine protease inhibitor family. CysC is a potent inhibitor of cathepsins - proteolytic enzymes that degrade intracellular and endocytosed proteins, remodel extracellular matrix, and trigger apoptosis. Inhibition is via tight reversible binding involving the $\mathrm{N}$-terminus as well as two $\beta$-hairpin loops of cysC. As a significant component of cerebrospinal fluid, cysC has numerous other functions, including support of neural stem cell growth and differentiation. Several studies suggest that cysC may bind to the Alzheimer-related protein beta-amyloid (A $\beta)$, and inhibit its aggregation and toxicity. Because of an increasing recognition of its important biological roles, there is considerable interest in methods to produce full-length recombinant human cysC. Several researchers have reported success, but with processes that require multiple purification steps. Here we report successful production of human cysC using an intein-based expression system and a simple one-column purification scheme. The recombinant protein so obtained was natively folded and active as an enzyme inhibitor. Unexpectedly, even mild concentration by ultrafiltration caused significant oligomerization. The oligomers are noncovalent and retain the native secondary structure and inhibitory activity of the monomer. The oligomers, but not the monomers, were highly effective at inhibiting aggregation of $A \beta$. These results demonstrate the critical importance of careful physicochemical characterization of recombinant cysC protein prior to evaluation of its biological functions.
\end{abstract}


Keywords: cystatin C, beta-amyloid, aggregation, oligomers, amyloid, light scattering

\begin{abstract}
Abbreviations: A $\beta$, beta-amyloid; AD, Alzheimer's disease; ANS, 8-Anilinonaphthalene-1sulfonic acid; catB, cathepsin B; CD, circular dichroism; cysC, cystatin C; DLS, dynamic light scattering; DTT, dithiothreitol; EDTA, ethylenediaminetetraacetic acid; MES, 2-(Nmorpholino)ethanesulfonic acid; MWCO, molecular weight cutoff; PBSA, phosphate buffered saline with azide; SDS, sodium dodecyl sulfate; Z-FR-AMC, N-carbobenzyloxy-phenylalaninearginine-7-amino-4-methylcoumarin
\end{abstract}




\section{Introduction}

Human cystatin $\mathrm{C}$ (cysC) is a soluble basic protein belonging to the cysteine protease inhibitor family. Relatively abundant in cerebrospinal fluid, the $13.3 \mathrm{kDa}$ protein (120 residues) is natively non-glycosylated and contains two disulfide bonds ${ }^{l}$. Each monomer contains a single five-stranded $\beta$-sheet encircling a lone $\alpha$-helix ${ }^{2}$. CysC is a potent inhibitor of cathepsins, which are proteolytic enzymes that are localized primarily to the endosomal/lysosomal system. Inhibition is via tight reversible binding involving the $\mathrm{N}$-terminus and two $\beta$-hairpin loops of cysC $^{3,4}$. Cathepsins degrade intracellular and endocytosed proteins, and serve a role in remodeling and degrading extracellular matrix. Leakage of cathepsin B (catB) to the cytosol leads to caspase activation and apoptosis ${ }^{5,6}$. Additionally, cathepsins are involved in adaptive immunity and angiogenesis, and a high level of cathepsin activity has been linked to neurological and cardiovascular disorders, and to tumor metastasis ${ }^{6}$, so cysC serves as a regulatory component in these processes. Since cysC is predominantly in circulating fluids while cathepsins are predominantly intracellular, cysC protects against widespread tissue damage due to proteolyis by leaked cathepsins. Besides its well-known cathepsin inhibitory activity, cysC inhibits mammalian legumain, an enzyme involved with antigen processing ${ }^{7}$. CysC also plays a role in neural stem cell growth and glial development ${ }^{8,9}$. Wildtype cysC is a component in the amyloid deposits found in patients with spontaneous cerebral amyloid angiopathy ${ }^{10}$. A single mutation (L68Q) renders cysC more prone to aggregate into amyloid fibrils and causes a hereditary cerebral amyloidosis leading to lethal hemorrhages ${ }^{11,12}$.

Several studies provide a specific link between cysC and the Alzheimer-related protein, beta-amyloid $(\mathrm{A} \beta)^{13}$. Aggregation of $\mathrm{A} \beta$ into amyloid fibrils and deposition in extracellular senile plaques is one of the defining characteristics of Alzheimer's disease (AD). CysC and A $\beta$ 
were found co-deposited in senile plaques of $\mathrm{AD}$ patients ${ }^{14}$, and soluble cysC-A $\beta$ complexes were detected in cerebrospinal fluid from $\mathrm{AD}$ patients ${ }^{15}$. CysC bound to $\mathrm{A} \beta$ and inhibited $\mathrm{A} \beta$ fibril formation in vitro ${ }^{16}$, reduced in vitro formation of soluble $\mathrm{A} \beta$ oligomers and protofibrils, and increased non-fibrillar insoluble aggregates ${ }^{17}$. Overexpression of cysC in transgenic APP mice led to a reduction in amyloid plaque deposition in vivo ${ }^{18} 19$. CysC partially protected neuroblastoma cells and primary cultured neurons from $\mathrm{A} \beta$ toxicity, although the protection was believed to be direct rather than via any effect on $A \beta$ aggregation ${ }^{20}$. Besides the direct interaction between cysC and $\mathrm{A} \beta$, the protease inhibitory activity of cys $\mathrm{C}$ may play a role in $\mathrm{AD}$. CysC expression in $\mathrm{AD}$ neurons is elevated, and the inhibitor is colocalized with catB ${ }^{21}$. CatB degrades $\mathrm{A} \beta$ into non-fibril-forming fragments, and this degradation is inhibited by cysC ${ }^{22,23}$.

Given the protein's important biological roles, several different strategies have been employed to produce full-length recombinant human cysC. Grubb and coworkers ${ }^{24,25}$ were the first to report production in E. coli. CysC was secreted into the bacterial periplasm and isolated using ion exchange chromatography followed by size exclusion chromatography. In an attempt to improve yield, Hayashi et al. ${ }^{26}$ used the peptide tag 4AaCter and codon optimization. Inclusion bodies containing the fusion protein were solubilized in urea, and the denatured protein was affinity purified on a metal affinity column. Following elution, the protein was refolded using a two-step dialysis scheme, then the peptide tag was cleaved by addition of a specific protease and the target protein was purified by ion exchange. Yield was approximately $7 \mathrm{mg}$ purified protein per liter culture. Zhang et al. ${ }^{27}$ took a different approach, producing the protein as a fusion product with maltose-binding protein to enhance solubility plus a His6 tag to allow for affinity purification. The soluble fusion product was purified by nickel chromatography, then reacted with protease to remove the His tag and maltose-binding protein, and re-purified on a 
nickel column, with the detagged protein recovered in the flowthrough. About $20 \mathrm{mg}$ fusion protein was obtained per L culture, with a final yield of about $9 \mathrm{mg} / \mathrm{L}$. Very recently, Zhou et al. ${ }^{28}$ expressed cysC as a fusion protein with $\mathrm{PelB}$, a self-cleaving signal sequence which directs the protein into the E. coli periplasm for disulfide-stabilized folding. Protein was purified from cell lysate by cation exchange followed by size exclusion chromatography, for a reported yield of 20 mg cysC per L culture. Alternatively, production of cysC in Pichia pastoris yeast-based expression system has been reported ${ }^{29,30}$, but this approach is less convenient than E. coli.

Here we report successful production of human cysC in E. coli using an intein-based expression system and a simple one-column purification scheme. The denatured fusion protein is captured by a chitin affinity column and refolded on-column. The folded protein is cleaved from the intein tag by a change in buffer $\mathrm{pH}$ and temperature, and easily eluted from the column. The recombinant protein so obtained was natively folded and active as an enzyme inhibitor. Unexpectedly, we found that mild concentration by ultrafiltration caused significant oligomerization. We report preliminary characterization of these cysC oligomers and their interaction with $A \beta$. Our results demonstrate the critical importance of careful physicochemical characterization of the cystatin $\mathrm{C}$ protein.

\section{Materials and Methods}

Cystatin C production and purification. The human cystatin $\mathrm{C}$ gene was codon-optimized for expression in E. coli using Genscript's OptimumGene algorithm (Supplementary Figure S1). The gene was synthesized with NruI and BamHI restriction sites at 5' and 3' positions, respectively, and ligated into the pTWIN1 plasmid (New England Biolabs). BL21-DE3 cells 
(New England Biolabs) were transformed with ligated plasmid and cultured in $500 \mathrm{~mL}$ of LB media containing $100 \mathrm{mg} / \mathrm{L}$ ampicillin. Protein expression was induced by addition of IPTG during mid log-phase growth. After 3 hours at $37^{\circ} \mathrm{C}$, the bacteria were harvested, pelleted, and re-suspended in lysis buffer $(20 \mathrm{mM}$ Tris-HCl, $500 \mathrm{mM} \mathrm{NaCl}, 1 \mathrm{mM}$ EDTA, $20 \mathrm{mM}$ PMSF, 1 mM DTT, pH 9.0, containing $8 \mathrm{M}$ urea). Cells were lysed by sonication for 15 minutes in an ice bath. Excess cell debris was pelleted by centrifugation and crude lysate was applied to a chitin affinity column (New England Biolabs) equilibrated to $4{ }^{\circ} \mathrm{C}(20 \mathrm{mM}$ Tris- $\mathrm{HCl}, 500 \mathrm{mM} \mathrm{NaCl}, 1$ mM EDTA, 1 mM DTT, pH 9.0, containing $4 \mathrm{M}$ urea). The column was thoroughly washed with buffer (20 mM Tris-HCl, $500 \mathrm{mM} \mathrm{NaCl}, 1 \mathrm{mM}$ EDTA, $\mathrm{pH}$ 9.0), to remove unbound material and to allow on-column refolding of bound protein. The column was equilibrated with elution buffer (20 mM Tris, $500 \mathrm{mM} \mathrm{NaCl}, 1 \mathrm{mM}$ EDTA, $\mathrm{pH}$ 6.5), then incubated at room temperature overnight to initiate cleavage. CysC was eluted from the column, dialyzed into PBSA (10 mM phosphate, $150 \mathrm{mM} \mathrm{NaCl}, 0.02 \% \mathrm{wt} / \mathrm{vol} \mathrm{NaN}_{3}, \mathrm{pH} 7.4$ ) overnight, and stored at $4{ }^{\circ} \mathrm{C}$. The mass spectrum was recorded by LC/MSD TOF (Agilent), using electrospray ionization.

$20 \mu \mathrm{l}$ each of cell lysate, chitin column flowthrough, and final cysC elution were mixed with 10X concentrated solutions of DTT and SDS (final concentration of $2 \% \mathrm{wt} / \mathrm{vol}$ SDS, $1 \mathrm{mM}$ DTT) and boiled for 5 minutes. For non-boiled and non-reduced samples, SDS only was added to a final concentration of $2 \% .12 \mu \mathrm{l}$ of each sample was loaded onto a 4-20\% gradient Bis-Tris gel (Thermo) and electrophoresed for 45 minutes at constant $125 \mathrm{~V}$. The gel was stained with Coomassie buffer $(0.1 \% \mathrm{wt} / \mathrm{vol}$ Coomassie brilliant blue R-250, 50\% vol/vol methanol, $10 \%$ $\mathrm{vol} / \mathrm{vol}$ glacial acetic acid) and destained overnight in destaining solution (50\% vol/vol methanol, $10 \% \mathrm{vol} / \mathrm{vol}$ glacial acetic acid). 
Centrifugal ultrafiltration. CysC as eluted from the chitin column was typically dilute ( $0.2 \mathrm{mg} / \mathrm{ml}$ ). The protein was concentrated via ultrafiltration at $4^{\circ} \mathrm{C}$ with a $3 \mathrm{kDa}$ MWCO regenerated cellulose membrane (Amicon-15, EMD Millipore) in a swinging-bucket rotor operated at 4,000 rpm for 15 minutes. Concentrations were determined by absorbance at $280 \mathrm{~nm}$ (NanoDrop 2000, Thermo), using a molar extinction coefficient of 11,100 $\mathrm{AU} \mathrm{cm}^{-1} \mathrm{M}^{-1} 31$. CysC was typically concentrated up to $1 \mathrm{mg} / \mathrm{ml}$ using this method.

In some experiments, concentrated cysC was ultrafiltered in a $30 \mathrm{kDa} \mathrm{MWCO}$ regenerated cellulose membrane filter device (Amicon-15, EMD Millipore). Centrifugal filtration devices were operated at 4,000 rpm for approximately 15 minutes at $4{ }^{\circ} \mathrm{C}$. Both filtrate and retentate were collected.

Dynamic light scattering $(D L S)$. CysC $(1 \mathrm{mg} / \mathrm{ml})$ was filtered through a $0.22 \mu \mathrm{m}$ filter (Merck Millex HV) directly into a scrupulously cleaned quartz cuvette. The cuvette was inserted into a BI-200SM goniometer (Brookhaven) with detector positioned at $90^{\circ}$ and viewing aperture opened to $400 \mu \mathrm{m}$ diameter. The cuvette temperature was maintained at $37^{\circ} \mathrm{C}$. Fluctuations in scattering intensity from a $150 \mathrm{~mW}, 488 \mathrm{~nm}$ laser source (Innova 90C-5, Coherent) were used to build the homodyne autocorrelation function (TurboCorr with 9KDLSW software, Brookhaven). Data were analyzed using the method of cumulants, to calculate a z-average hydrodynamic diameter, and the CONTIN NNLS algorithm, to determine the particle size distribution. The total scattered intensity at $90^{\circ}$ was also measured; scattering from buffer was measured and subtracted from the sample scattered intensity.

Glutaraldehyde crosslinking. CysC was diluted to $20 \mu \mathrm{M}$ with PBSA. Glutaraldehyde stock solution (50\% vol/vol, Sigma) was diluted in half with PBSA, then mixed with $50 \mu \mathrm{l}$ 
protein to a final concentration of $1 \%$ glutaraldehyde and incubated at room temperature for 1 minute. The crosslinking reaction was quenched by addition of $\mathrm{NaBH}_{4}(7 \% \mathrm{wt} / \mathrm{vol}$, Sigma) to a final concentration of $0.28 \%$. SDS and DTT were added to the samples (final concentration $2 \%$ wt/vol SDS, $1 \mathrm{mM}$ DTT), and the samples were boiled for 5 minutes before loading onto a 4$20 \%$ Bis-Tris gradient gel (Thermo). Electrophoresis was performed for 40 minutes at constant 125 V. Gels were fixed and stained using a silver stain kit (Pierce).

Circular dichroism $(C D)$ spectroscopy. CysC $(20 \mu \mathrm{M})$ was extensively dialyzed into fluoride-containing buffer (10 mM phosphate, $50 \mathrm{mM} \mathrm{NaF}, \mathrm{pH}$ 7.4). CD spectra of monomers and oligomers were measured on an Aviv model 420 CD spectrometer between $190-250 \mathrm{~nm}$. Measurements from filtered fluoride buffer were subtracted from the protein samples. CD spectra were analyzed using the CONTINLL algorithm [Sreerama, 2000], using SP43 as the basis set.

Transmission electron microscopy (TEM). Samples were diluted to $10 \mu \mathrm{M}$ with PBSA, fixed on a pioloform-coated grid, and stained with methylamine tungstate. Images were taken by with a Philips CM120 scanning transmission electron microscope (FEI Corp.).

Enzymatic activity assays. Enzyme inhibitory activity was evaluated against papain and catB. Lyophilized papain (Sigma) was reconstituted to $2 \mathrm{mg} / \mathrm{ml}$ in Tris assay buffer (50 $\mathrm{mM}$ Tris-HCl, $\mathrm{pH} 7.0$, containing $0.02 \%$ Tween 20 to prevent nonspecific protein adsorption ${ }^{32}$. Papain was activated by addition of $5 \mathrm{mM}$ DTT and room temperature incubation for 15 minutes. Cathepsin B (0.437 mg/ml, Enzo) was diluted to $3.4 \mu \mathrm{M}$ into MES assay buffer (25 mM MES, 1 mM EDTA, 1 mM DTT, $0.02 \%$ Tween 20, pH 6.0) and activated by addition of 5 mM DTT ${ }^{33}$. 
CysC $(15 \mu \mathrm{M})$ was diluted into Tris (papain assay) or MES (cathepsin B assay) buffer to $40-800 \mathrm{nM}$ and mixed with activated papain $(400 \mathrm{nM})$ or cathepsin B $(200 \mathrm{nM})$ in equal volume. Mixtures were incubated at $37{ }^{\circ} \mathrm{C}$ for 10 minutes, then diluted ten-fold in either Tris (papain) or MES (cathepsin B) assay buffer. Freshly-prepared fluorogenic substrate, Z-FR-AMC (R\&D Systems, $200 \mu \mathrm{M}$ in Tris or MES assay buffer) was added in equal volume to protein samples in a black polystyrene 96-well plate. The final concentrations of papain and cathepsin B were nominally $10 \mathrm{nM}$ and $5 \mathrm{nM}$, respectively. CysC concentrations ranged from $0-20 \mathrm{nM}$. Fluorescence measurements were taken continuously in an FL800 plate reader (Biotek) for 5 minutes, using excitation and emission wavelengths of $360 \mathrm{~nm}$ and $460 \mathrm{~nm}$, respectively. Initial reaction rates $v$ were calculated by linear regression of fluorescence rate of increase and normalized to $V_{0}$, the reaction rate in the absence of inhibitor. Samples were prepared in duplicate in each assay. Reported data is the average over 3 (papain) or 4 (cathepsin B) independent assays.

The apparent inhibition constant, $K_{i, a p p}$, and the total concentration of active enzyme, $[E]$, were determined by least-squares fitting of $v / V_{0}$ versus the total cysC concentration $[I]$ to the Morrison equation for tight-binding competitive enzyme inhibition (eq. 1) ${ }^{34,35}$ :

$$
\frac{v}{V_{o}}=\frac{[E]-[I]-K_{i, a p p}+\sqrt{\left([E]-[I]-K_{i, a p p}\right)^{2}+4[E] K_{i, a p p}}}{2[E]}
$$

The true inhibition constant $K_{i}$ was determined from $K_{i, a p p}$ and the substrate concentration [S] by:

$$
K_{i}=K_{i, a p p} /\left(1+\frac{[S]}{K_{M}}\right)
$$


$K_{m}$ was measured by titration of Z-FR-AMC against $5 \mathrm{nM}$ enzyme. Briefly, substrate was prepared at concentrations between 0 and $100 \mu \mathrm{M}$ in either Tris assay buffer (papain) or MES assay buffer (cathepsin B). Activated enzyme was added, and initial reaction rates were determined by continuous fluorescence measurements as previously described. Plots of substrate concentration versus initial reaction rate were fit to the Michaelis-Menton rate expression, with $K_{m}$ and $V_{o, \max }$ as fitting parameters.

A $\beta$ interaction studies. Lyophilized A $\beta(1-40)$ (AnaSpec, San Jose, California) was reconstituted to $2.8 \mathrm{mM}$ in denaturing buffer (100 mM glycine, $8 \mathrm{M}$ urea, $\mathrm{pH}$ 10, filtered through $0.22 \mu \mathrm{m}$ Millex PVDF syringe filter) to fully disaggregate the peptide ${ }^{36}$. Refolding and aggregation of $\mathrm{A} \beta$ was initiated by rapid dilution to $28 \mu \mathrm{M}$ in PBSA (10 mM phosphate, $150 \mathrm{mM}$ $\mathrm{NaCl}, 0.02 \% \mathrm{wt} / \mathrm{vol} \mathrm{NaN}, \mathrm{pH} 7.4$, filtered through $0.22 \mu \mathrm{m}$ Millex PVDF syringe filter). Alternatively, $\mathrm{A} \beta$ was rapidly diluted to $28 \mu \mathrm{M}$ in PBSA containing either cysC monomers or oligomers. The final concentration of cysC was $14 \mu \mathrm{M}$ (monomer basis). Each sample was filtered (0.22 $\mu \mathrm{m}$ Millex PVDF) directly into a clean cuvette immediately prior analysis by DLS. Sample temperatures were held constant at $37{ }^{\circ} \mathrm{C} . \mathrm{A} \beta$ aggregate growth in all samples was monitored for 2 hours using 5-minute autocorrelation averaging periods. The normalized scattering intensity was calculated by subtracting the buffer scattering from the sample scattering intensity and then dividing by the total protein concentration in each sample.

ANS fluorescence. CysC was mixed with ANS (final concentrations of $1 \mu \mathrm{M}$ protein, 28 $\mu \mathrm{M}$ ANS in PBSA) and incubated at room temperature for 10 minutes. Samples were excited at $370 \mathrm{~nm}$ and emission spectra were recorded for $440-500 \mathrm{~nm}$ (QuantaMaster 40, PTI). The 
emission spectrum of PBSA was recorded and subtracted from each sample using FelixGX software.

\section{Results}

Cystatin C production and purification. Expression of cystatin C in the pTWIN1 plasmid produces a fusion protein that, at high $\mathrm{pH}$ and $4^{\circ} \mathrm{C}$, binds to a chitin affinity column.

Denaturation with urea was necessary in order for the fusion protein to bind to the chitin column. After adsorption, washing with cold buffer at $\mathrm{pH} 9$ removed the urea, allowing on-column refolding. At low $\mathrm{pH}$ and room temperature, the intein tag undergoes $\mathrm{C}$-terminal peptide bond cleavage, releasing full-length cysC (Supplementary Figure S2). Figure 1 shows SDS-PAGE analysis of cell lysate, column flowthrough, and eluted cysC. The fusion protein is at high concentration in the cell lysate, along with some cysC and intein tag $(30 \mathrm{kDa})$ due to premature cleavage. Most of the fusion protein is captured by the chitin affinity column, whereas the untagged cysC is in the flowthrough. Highly purified cysC is obtained upon elution. In a typical $500 \mathrm{~mL}$ batch fermentation, $25 \mathrm{~mL}$ of $0.2-0.3 \mathrm{mg} / \mathrm{mL}$ cysC was collected in the chitin column elution, for a yield of 10-15 mg pure protein per $\mathrm{L}$ of culture.

Purified protein was analyzed by mass spectrometry (Supplemental Figure S3). The expected molecular mass $(13,343 \mathrm{Da})$ is the predominant component of the sample. Small peaks of singly oxidized (13,359 Da) and doubly oxidized (13,374 Da) cysC were present. These are likely due to methionine oxidation ${ }^{37}$, which also occurs in vivo, possibly accumulating during 
the aging process ${ }^{38}$. No other peak was detected, demonstrating that cysC was not truncated or degraded during purification and storage.

Discovery of cystatin C oligomers. Purified cysC was concentrated to $1 \mathrm{mg} / \mathrm{ml}$ by ultrafiltration in a $3 \mathrm{kDa}$ MWCO centrifuge filter, and protein hydrodynamic diameter was measured by DLS. Based on a spherical geometry and a specific volume of $1.1 \mathrm{~mL} / \mathrm{g}$ for hydrated protein, we calculated an expected hydrodynamic diameter of $3.6 \mathrm{~nm}$ for cysC monomers, a number that is consistent with pulse-field gradient NMR measurements ${ }^{39}$. For our sample (representative chosen from 5 replicates), the z-average hydrodynamic diameter was 9.9 $\mathrm{nm}$ (polydispersity of 0.22 ). Further analysis of the autocorrelation function to obtain an intensity-weighted particle size distribution revealed a bimodal distribution, with a major peak centered at $7 \mathrm{~nm}$ and a minor peak centered around $28 \mathrm{~nm}$ (Figure 2a). These data indicate that concentrated solutions of cysC contain small oligomers (dimers, $4.5 \mathrm{~nm}$ diameter, to $\sim 12$-mers, 8 $\mathrm{nm}$ diameter, assuming solid spheres) as well as a small population of larger aggregates. The intensity distribution is weighted according to the scattering intensity, and is the most natural representation of the data. The mass-weighted distribution (Figure $2 b$ ) is a transformation of the intensity distribution, assuming particles are hard spheres of constant density. This representation shows that nearly all of the mass is present as small oligomers.

The stability of the oligomers was investigated by diluting the sample and measuring its light scattering intensity. Since scattering intensity is a linear function of mass concentration and a sixth-order function of particle size, any dissociation of aggregates should sharply reduce the total scattering intensity of the sample. The observed relationship between dilution and scattering intensity was linear (data not shown), indicating that the aggregates did not dissociate within a two-day time period. 
Separation of monomeric cysC from oligomers. To further establish the existence of oligomers, we crosslinked protein solutions using glutaraldehyde. (In preliminary experiments, the crosslinking time was optimized to capture stable oligomers while minimizing unwanted crosslinking of dimers arising from random collisions, data not shown.) As eluted from the chitin column, cysC contains approximately equal-density bands of monomer and dimer, as well as a weak trimer band (Figure 3a, lane 1). After concentration by ultrafiltration in a $3 \mathrm{kDa}$ MWCO membrane, some larger oligomers appear as a high-molecular-weight 'smear' (lane 2). To separate monomer from oligomers, the concentrated cysC was filtered through a nominal 30 kDa MWCO centrifuge filter. (Size exclusion chromatography was not used for fractionation, because of the dilution that occurs.) The filtrate and retentate were collected, adjusted to the same concentration, reacted with glutaraldehyde to crosslink any multimers, then analyzed by SDS-PAGE. After size fractionation through a $30 \mathrm{kDa}$ MWCO ultrafiltration membrane, the filtrate is predominantly monomer, with some dimer (lane 3$)$. The dimer ( $27 \mathrm{kDa})$ could partially permeate through the nominal $30 \mathrm{kDa}$ filter; in addition, some collision-induced crosslinking is possible. The filtrate (monomer) was re-concentrated by $3 \mathrm{kDa}$ ultrafiltration, after which aggregates re-appeared (lane 4). The retentate contained some monomer but also a high fraction of dimers and larger multimers (lane 5). In the absence of crosslinking, all samples ran as pure monomers, either in the absence or presence of DTT and boiling (Figure 3b). This result indicates that the multimers are SDS-soluble and noncovalent, and are not formed by incorrect disulfide bond formation.

To further demonstrate that oligomers form during the concentration process, monomeric cysC $(8 \mu \mathrm{M})$ was ultrafiltered to varying degrees of concentration. Samples were taken at low (1.12-fold), moderate (2-fold), and high (5.6-fold) concentration ratios. Each sample was diluted 
back to $8 \mu \mathrm{M}$, then fixed, stained, and imaged by TEM (Figure 4). In the monomeric starting material or at the 1.12-fold concentration ratio, no aggregates were apparent (Figure 4a,b). Small globular clusters began to appear at $16 \mu \mathrm{M}$ (Figure 4c). At the highest concentration ratio (Figure 4d), small globular clusters and larger 'wormlike' aggregates were observed. The small globular clusters are $\sim 5-10 \mathrm{~nm}$ in diameter, consistent with light scattering observations (Figure 2). The larger aggregates could belong to the $\sim 30 \mathrm{~nm}$ population seen by DLS.

Characterization of cysC monomer and oligomers. We next compared the physicochemical properties of fractionated monomer and oligomer solutions. $10 \mathrm{~mL}$ cysC (15 $\mu \mathrm{M}$ ) was concentrated to $1 \mathrm{~mL}$ via ultrafiltration in a $3 \mathrm{kDa}$ filter. $4 \mathrm{~mL}$ PBSA was added to the concentrated protein, then the sample was centrifuged through a $30 \mathrm{kDa}$ filter. $4.5 \mathrm{~mL}$ (primarily) monomeric cysC $(22 \mu \mathrm{M})$ was collected in the filtrate, while $0.5 \mathrm{~mL}$ of oligomercontaining cysC $(70 \mu \mathrm{M})$ was collected in the retentate. Thus, about $67 \%$ of the mixture was recovered as a monomer-rich fraction, $23 \%$ as an oligomer-rich fraction, and $10 \%$ was lost during handling.

CD spectra were virtually identical for the monomer and oligomer fractions (Figure 5, Table 1). The secondary structure determination was consistent with that obtained by NMR, crystallography, and FT-IR ${ }^{2,39,40}$, demonstrating that both monomer and oligomer fractions attain native secondary structure. Trp fluorescence emission spectra were similar for the monomeric and oligomeric fractions, with peak fluorescence intensity at $345 \mathrm{~nm}$ (data not shown), indicating that the environment around the lone tryptophan does not change, consistent with retention of native tertiary structure. 
Natively folded cysC contains a pair of loops characteristic of the cystatin superfamily. These two loops, along with the flexible N-terminal domain, dock into substrate binding grooves of the cysteine protease and inhibit enzyme activity ${ }^{41}$. Inhibition is from tight binding at a 1:1 stoichiometry. Inhibitor activity is lost in incorrectly folded cysC, including domain-swapped dimers ${ }^{42}$. Monomer and oligomer inhibitory activity against papain and human catB were determined as a function of cysC concentration (Figure 6). The data were fit to Eq. 1 to determine $K_{i}$ (Table 2). The very tight binding we observed for papain is consistent with previously reported kinetic measurements ${ }^{31}$ and should be taken as a limiting (maximum) value. With catB, $K_{i}$ for cysC monomers and oligomers are not statistically different $(p<0.05, n=4)$ and are consistent with literature values $(80-260 \mathrm{pM})^{3,27,33,43}$. The modest apparent decrease in inhibitory activity for the oligomer-rich fraction could be due to the reduction in effective concentration due to oligomerization.

Given no differences in secondary or tertiary structure, or in biological activity, we tested for any difference in the surface properties by measuring the fluorescence of ANS. ANS binds to hydrophobic patches or cavities in proteins; binding greatly increases the fluorescence intensity ${ }^{44}$. Here we observed a significant difference: Monomeric cysC did not affect ANS fluorescence, whereas the oligomeric protein caused a large increase in intensity (Figure 7). This suggests that the oligomerization of cysC leads to coordination of hydrophobic residues into patches or cavities to which ANS may bind.

Oligomer formation during purification. Our data show that cysC oligomers will form from purified monomer during concentration by ultrafiltation. We next asked whether oligomers form earlier, during purification, and, if so, at what step. We hypothesized that oligomers could form on the beads during adsorption, or during the cleavage/elution step. To test these 
alternatives, we examined the effect of protein concentration during adsorption and during cleavage and elution. Crude cell lysate supernatant (20 ml, in lysis buffer) was prepared as usual, combined with $20 \mathrm{ml}$ of wash buffer, and then split into three batches of $10 \mathrm{ml}$ each. $5 \mathrm{ml}$ of packed chitin beads were assigned to each batch of lysate. The first batch of lysate was purified exactly as described earlier as a control. Briefly, the lysate was applied directly to the cold chitin beads and allowed to incubate for 1 hour before washing and equilibrating with $10 \mathrm{~mL}$ cold elution buffer. After an overnight incubation at room temperature, the protein was eluted by flushing $10 \mathrm{ml}$ elution buffer through the column. The second batch of lysate was diluted to 40 $\mathrm{ml}$ (using chitin equilibration buffer to maintain constant urea concentration), reducing by 4-fold the protein concentration during adsorption. The chitin beads were transferred to a $50 \mathrm{ml}$ tube and the diluted lysate was added. The tube was gently shaken at $4{ }^{\circ} \mathrm{C}$ for one hour to allow adsorption to the chitin beads. Given the lower protein concentration in the lysate, the adsorbed surface concentration on the beads should also be lower than under control conditions. The beads were transferred back to the column and allowed to settle, then $10 \mathrm{~mL}$ cold elution buffer was added and the column was incubated at room temperature overnight. $10 \mathrm{ml}$ of eluent was collected. For the third batch of lysate, protein was adsorbed from the cell lysate as in the control, but the final elution buffer volume was increased 4-fold to $40 \mathrm{ml}$. The beads were removed from the column, transferred to a $50 \mathrm{ml}$ tube, and then mildly shaken at room temperature overnight in order to facilitate transfer of the cleaved protein from the bead surface to the bulk solution. In this case, the protein concentration during cleavage and elution is one-fourth that of the control conditions.

After extensive dialysis of eluted protein into PBSA, samples were diluted to the same final protein concentration, and ANS fluorescence intensity was used to measure oligomer 
content (Figure 8). The decrease in concentration during cleavage and elution (third batch) had only a minor effect on the oligomer content. In contrast, dilution of the cell lysate and reduction of the adsorbed protein density significantly reduced oligomer content. These results indicate that cysC oligomers form during purification due to the locally high concentration on the beads. Along with the results from ultrafiltration experiments, these data together indicate that cysC is prone to oligomer formation during any process that concentrates the protein.

Effect of cysC on beta-amyloid aggregation. Several reports have provided evidence that cysC plays a role in preventing amyloid development during Alzheimer's disease progression ${ }^{13}$, by binding to $A \beta$ and inhibiting $A \beta$ fibril formation and growth ${ }^{16,17,45}$. We examined whether our cysC preparations (monomer or oligomeric) were able to slow A $\beta$ aggregation, using DLS to measure the mean hydrodynamic diameter of aggregates. Additionally, the normalized scattering intensity, which is approximately proportional to the average molecular weight of aggregates, was measured. Scattering from cysC monomer alone $(14 \mu \mathrm{M})$ was weak, insufficient to build an autocorrelation function. No aggregation was found over 2 hours (data not shown). For cysC oligomeric fraction $(14 \mu \mathrm{M})$, the z-average hydrodynamic diameter was $\sim 12 \mathrm{~nm}$, and neither the diameter nor the total scattering intensity and hydrodynamic diameter changed over 2 hours (not shown). With $A \beta$ alone $(28 \mu \mathrm{M})$, both the mean size and the intensity increased over the 2 -h time period, indicative of the expected growth in both size and number of A $\beta$ aggregates (Figure 9). $\mathrm{A} \beta$ aggregated at a similar rate in the presence of monomeric cys $C$; in fact, mean $\mathrm{A} \beta$ aggregate hydrodynamic diameter was greater in the presence of cysC. In striking contrast, oligomeric cys $\mathrm{C}$ completely prevented $\mathrm{A} \beta$ aggregation: The hydrodynamic diameter remained constant at $\sim 12 \mathrm{~nm}$ over the 2-hr observation window. Total scattering intensity was higher initially than for 
either $\mathrm{A} \beta$ alone or with monomeric cysC, was similar to oligomeric cysC alone (not shown), and did not change with time (Figure 9b).

\section{Discussion}

Cystatin $\mathrm{C}$ is a well-known member of the cysteine protease inhibitor family and also inhibits legumain, an aspargine-specific endoprotease. Increasingly, it is becoming clear that cystatin $\mathrm{C}$ serves myriad functions, in regulating neural stem cell differentiation, extracellular

matrix remodeling, angiogenesis, and tumor metastasis ${ }^{1,5,6,9}$. It is an unusual circulating protein in that it is more concentrated in cerebrospinal fluid than in plasma, with a typical CSF concentration of $7 \mathrm{mg} / \mathrm{L}$ (about $0.5 \mu \mathrm{M})^{46}$.

Given the biological importance of cysC, there has been renewed interest in methods of recombinant production of the protein in E. coli. Three recent papers illustrate different approaches ${ }^{26-28}$, with reported yields of purified proteins from batch fermentation of 7-20 mg/L. In two of these methods, a fusion protein was produced, and purification required two different adsorption steps as well as an intermediate cleavage step (plus refolding, in one case) in solution. We report here successful adoption of a simpler one-step approach, in which adsorption, cleavage of the tag, and refolding all occur on a single column. Our approach resulted in good yield (10-15 mg/L) of highly pure and active cystatin C.

As one step in our purification process, we (like others) used centrifugal ultrafiltration to concentrate the protein. We observed that, above $\sim 20 \mu \mathrm{M}$, small oligomers formed. These oligomers are noncovalent and SDS-soluble, so are not detected by standard gel electrophoresis, the technique used by most researchers to show size and purity. The oligomers retain native 
secondary and tertiary structure. Furthermore, they inhibit papain and cathepsin B with equal activity as the separated monomers. Since by these commonly used assays the oligomers are not detectable, we suspect that other researchers may unknowingly have oligomers in their protein preparations. Grubb and coworkers have established that, at low $\mathrm{pH}$, high temperature, or in the presence of chemical denaturant, cysC will form domain-swapped dimers ${ }^{47}$. These domainswapped dimers differ from monomers in their CD spectra, and are inactive in cysteine protease inhibition assays. Thus, the oligomers we observe are not domain-swapped, and represent a distinctly different class of cysC multimers.

$\mathrm{Cys} \mathrm{C}$ oligomers were formed during purification from the cell lysate, and again when purified monomers were re-concentrated by ultrafiltration. Our study of different purification schemes showed that reducing the protein concentration during adsorption also reduced cysC oligomerization. These experiments indicate that cysC oligomers may form during any step in which the protein is exposed to locally high concentrations, either due to a high adsorbed density on the chitin bead surface, or concentration polarization at the ultrafiltration membrane surface. In preliminary experiments, we concentrated cysC by slow dialysis against polyethylene glycol (3500 MWCO dialysis tubing, $100 \mathrm{mg} / \mathrm{ml} \mathrm{PEG-20} \mathrm{in} \mathrm{PBSA),} \mathrm{which} \mathrm{removes} \mathrm{water} \mathrm{because} \mathrm{of}$ osmotic pressure. We were able to achieve 4-fold concentration (10 $\mu \mathrm{M}$ to $40 \mu \mathrm{M})$ without significant aggregation, presumably because the slow flux limited concentration polarization at the tubing surface.

Several groups have reported that cysC interacts with $A \beta$ and may play a role in inhibiting $A \beta$ fibrillogenesis and toxicity in Alzheimer's disease ${ }^{13,16-18,20,22}$. We used light scattering to probe, in solution and non-invasively, for evidence for inhibition of aggregation. We observed remarkably different behaviors of monomeric versus oligomeric cysC. Interestingly, 
the oligomeric cys $C$ inhibited aggregation of $A \beta$, while the monomeric cys $C$ did not. To discover a possible explanation for this, we tested the surface properties and found that cysC oligomers bind ANS strongly whereas cysC monomers do not. This suggests that the oligomerization of cysC leads to coordination of hydrophobic residues into patches or cavities to which ANS, and $\mathrm{A} \beta$, may bind. Binding of $\mathrm{A} \beta$ to these patches or cavities of cysC oligomers would effectively sequester $A \beta$ and prevent amyloid from forming. This finding, that interactions with $A \beta$ depend strongly on the cysC oligomer status, has important implications for designing and interpreting experiments in which the mechanisms of cysC and $\mathrm{A} \beta$ interactions are probed.

\section{Acknowledgements}

Funding was provided by the National Science Foundation CBET-1262729. CD spectra were obtained at the University of Wisconsin-Madison Biophysics Instrumentation Facility, which was established with support from the University of Wisconsin-Madison and granst BIR9512577 (NSF) and S10 RR13790 (NIH), with technical assistance provided by Dr. Darrell McCaslin. Randall Massey provided technical assistance with TEM. 
Table 1. Secondary structure elements (\%) of cystatin C determined by analysis of CD spectra

$\begin{array}{ccccc} & \alpha \text {-Helix } & \beta \text {-Sheet } & \text { Turn } & \text { Disorder } \\ \text { monomer } & 15 & 31 & 21 & 34 \\ \text { oligomer } & 11 & 33 & 22 & 34\end{array}$


Table 2. Cystatin $\mathrm{C}$ inhibition equilibrium constants from enzymatic assays.

Values given are mean \pm standard error.

$\begin{array}{llll}\text { Enzyme } & K_{m}(\mu \mathrm{M}) & \text { CysC fraction } & K_{i}(\mathrm{pM}) \\ \text { Papain } & 110 \pm 10 & \text { monomer } & <5 \pm 4 \\ & & \text { oligomer } & <7 \pm 5 \\ \text { Cathepsin B } & 22 \pm 3 & \text { monomer } & 60 \pm 20 \\ & & \text { oligomer } & 100 \pm 30\end{array}$




\section{Figure Legends}

Figure 1. Reducing SDS-PAGE of cell lysate (lane 1), chitin column flow-through (lane 2), and chitin column elution after washing and flushing with elution buffer at room temperature (lane 3).

Figure 2. Size distribution of purified cystatin C. Hydrodynamic diameter distribution was determined by CONTIN analysis of autocorrelation functions. (a) Intensity- and (b) massweighted distributions.

Figure 3. (a) SDS-PAGE of glutaraldehyde-crosslinked cysC, showing purification of monomers from oligomers. Lane 1: Chitin column elution. Lane 2: Concentration by $3 \mathrm{kDa}$ ultrafiltration. Lane 3: Filtrate of $30 \mathrm{kDa}$ ultrafiltration. Lane 4: Concentration of filtrate of lane 3 by $3 \mathrm{kDa}$ ultrafiltration. Lane 5: Retentate of $30 \mathrm{kDa}$ ultrafiltration. Each lane contains $2.5 \mu \mathrm{g}$ total protein. (b) Comparison of reducing and non-reducing conditions. Lane 1: Filtrate (monomer-rich) fraction, reduced and boiled. Lane 2: Filtrate (monomer-rich) fraction, non-reduced, not boiled. Lane 3: Retentate (oligomer-rich) fraction, reduced and boiled. Lane 4: Retentate (oligomer-rich) fraction, non-reduced and not boiled. Each lane contains $3 \mu \mathrm{g}$ total protein.

Figure 4. TEM images of purified monomeric cysC after various stages of concentration via ultrafiltration using a $3 \mathrm{kDa}$ MWCO membrane. Monomeric cysC, initially at $8 \mu \mathrm{M}$ (a) was ultrafiltered to the following final concentrations: $9 \mu \mathrm{M}$ (b), $16 \mu \mathrm{M}$ (c), and $45 \mu \mathrm{M}$ (d). Each sample was diluted back to $8 \mu \mathrm{M}$ prior to TEM imaging. Each scale bar is $200 \mathrm{~nm}$.

Figure 5. CD spectra of monomeric cysC (solid line) and the fraction containing oligomers (dashed line). 
Figure 6. Purified cysC monomer (ם) and oligomers ( $\square$ ) were tested for biological activity against $10 \mathrm{nM}$ papain (a) and $5 \mathrm{nM}$ cathepsin $\mathrm{B}$ (b). The cysC concentration is given as equivalent monomer. Error bars represent standard deviation of 4 replicates.

Figure 7. Fluorescence spectra of ANS incubated with purified monomeric (solid line) or oligomer-rich (dashed line) cysC. Excitation wavelength was $370 \mathrm{~nm}$.

Figure 8. ANS fluorescence of cysC produced during modified purification methods: standard method (solid line), diluted cell lysate (dotted line), and diluted elution buffer (dashed line). The data shown are an average of two independent scans. Protein concentration is $1 \mu \mathrm{M}$ protein, with $28 \mu \mathrm{M}$ ANS.

Figure 9. Effect of cysC aggregation state on $\mathrm{A} \beta$ aggregation rate as measured by DLS. Effective hydrodynamic diameter (a) and normalized scattering intensity (b) were measured for $\mathrm{A} \beta$ alone $(\triangle), \mathrm{A} \beta$ incubated with monomeric cysC $(\mathrm{X})$, or $\mathrm{A} \beta$ incubated with oligomeric cysC (ם). A $\beta$ concentration was $28 \mu \mathrm{M}$. CysC concentration (monomeric or oligomer-rich) was 14 $\mu \mathrm{M}$ on a monomer basis. Representative of 3 repeats. The scattered intensity is normalized to account for the different concentrations of total protein in the samples. 


\section{References}

[1] Mussap, M., and Plebani, M. (2004) Biochemistry and clinical role of human cystatin C, Crit Rev Cl Lab Sci 41, 467-550.

[2] Kolodziejczyk, R., Michalska, K., Hernandez-Santoyo, A., Wahlbom, M., Grubb, A., and Jaskolski, M. (2010) Crystal structure of human cystatin C stabilized against amyloid formation, Febs J 277, 1726-1737.

[3] Hall, A., Hakansson, K., Mason, R. W., Grubb, A., and Abrahamson, M. (1995) Structural Basis for the Biological Specificity of Cystatin-C - Identification of Leucine-9 in the N-Terminal Binding Region as a Selectivity-Conferring Residue in the Inhibition of Mammalian Cysteine Peptidases, J Biol Chem 270, 5115-5121.

[4] Nycander, M., Estrada, S., Mort, J. S., Abrahamson, M., and Bjork, I. (1998) Two-step mechanism of inhibition of cathepsin B by cystatin $C$ due to displacement of the proteinase occluding loop, Febs Lett 422, 61-64.

[5] Lutgens, S. P. M., Cleutjens, K. B. J. M., Daemen, M. J. A. P., and Heeneman, S. (2007) Cathepsin cysteine proteases in cardiovascular disease, Faseb J 21, 3029-3041.

[6] Turk, V., Stoka, V., Vasiljeva, O., Renko, M., Sun, T., Turk, B., and Turk, D. (2012) Cysteine cathepsins: From structure, function and regulation to new frontiers, Bba-Proteins Proteom 1824, 68-88.

[7] Alvarez-Fernandez, M., Barrett, A. J., Gerhartz, B., Dando, P. M., Ni, J. A., and Abrahamson, M. (1999) Inhibition of mammalian legumain by some cystatins is due to a novel second reactive site, $J$ Biol Chem 274, 19195-19203.

[8] Taupin, P., Ray, J., Fischer, W. H., Suhr, S. T., Hakansson, K., Grubb, A., and Gage, F. H. (2000) FGF-2responsive neural stem cell proliferation requires $\mathrm{CCg}$, a novel autocrine/paracrine cofactor, Neuron 28, 385-397.

[9] Hasegawa, A., Naruse, M., Hitoshi, S., Iwasaki, Y., Takebayashi, H., and Ikenaka, K. (2007) Regulation of glial development by cystatin C, J Neurochem 100, 12-22.

[10] McCarron, M. O., Nicoll, J. A. R., Stewart, J., Ironside, J. W., Mann, D. M. A., Love, S., Graham, D. I., and Grubb, A. (2000) Absence of cystatin C mutation in sporadic cerebral amyloid angiopathyrelated hemorrhage, Neurology 54, 242-244.

[11] Olafsson, I., and Grubb, A. (2000) Hereditary cystatin C amyloid angiopathy, Amyloid 7, 70-79.

[12] Palsdottir, A., Snorradottir, A. O., and Thorsteinsson, L. (2006) Hereditary cystatin C amyloid angiopathy: Genetic, clinical, and pathological aspects, Brain Pathol 16, 55-59.

[13] Kaur, G., and Levy, E. (2012) Cystatin C in Alzheimer's disease, Front Mol Neurosci 5.

[14] Levy, E., Sastre, M., Kumar, A., Gallo, G., Piccardo, P., Ghetti, B., and Tagliavini, F. (2001) Codeposition of cystatin $\mathrm{C}$ with amyloid-beta protein in the brain of Alzheimer disease patients, J Neuropath Exp Neur 60, 94-104.

[15] Mi, W. Q., Jung, S. S., Yu, H., Schmidt, S. D., Nixon, R. A., Mathews, P. M., Tagliavini, F., and Levy, E. (2009) Complexes of Amyloid-beta and Cystatin C in the Human Central Nervous System, J Alzheimers Dis 18, 273-280.

[16] Sastre, M., Calero, M., Pawlik, M., Mathews, P. M., Kumar, A., Danilov, V., Schmidt, S. D., Nixon, R. A., Frangione, B., and Levy, E. (2004) Binding of cystatin C to Alzheimer's amyloid beta inhibits in vitro amyloid fibril formation, Neurobiol Aging 25, 1033-1043.

[17] Selenica, M. L., Wang, X., Ostergaard-Pedersen, L., Westlind-Danielsson, A., and Grubb, A. (2007) Cystatin $C$ reduces the in vitro formation of soluble $A$ beta 1-42 oligomers and protofibrils, Scand J Clin Lab Inv 67, 179-190. 
[18] Kaeser, S. A., Herzig, M. C., Coomaraswamy, J., Kilger, E., Selenica, M. L., Winkler, D. T., Staufenbiel, M., Levy, E., Grubb, A., and Jucker, M. (2007) Cystatin C modulates cerebral beta-amyloidosis, Nat Genet 39, 1437-1439.

[19] Mi, W., Pawlik, M., Sastre, M., Jung, S. S., Radvinsky, D. S., Klein, A. M., Sommer, J., Schmidt, S. D., Nixon, R. A., Mathews, P. M., and Levy, E. (2007) Cystatin C inhibits amyloid-beta deposition in Alzheimer's disease mouse models, Nat Genet 39, 1440-1442.

[20] Tizon, B., Ribe, E. M., Mi, W. Q., Troy, C. M., and Levy, E. (2010) Cystatin C Protects Neuronal Cells from Amyloid-beta-induced Toxicity, J Alzheimers Dis 19, 885-894.

[21] Deng, A., Irizarry, M. C., Nitsch, R. M., Growdon, J. H., and Rebeck, G. W. (2001) Elevation of cystatin $C$ in susceptible neurons in Alzheimer's disease, Am J Pathol 159, 1061-1068.

[22] Sun, B. G., Zhou, Y. G., Halabisky, B., Lo, I., Cho, S. H., Mueller-Steiner, S., Devidze, N., Wang, X., Grubb, A., and Gan, L. (2008) Cystatin C-Cathepsin B Axis Regulates Amyloid Beta Levels and Associated Neuronal Deficits in an Animal Model of Alzheimer's Disease, Neuron 60, 247-257.

[23] Wang, C., Sun, B. G., Zhou, Y. G., Grubb, A., and Gan, L. (2012) Cathepsin B Degrades Amyloid-beta in Mice Expressing Wild-type Human Amyloid Precursor Protein, J Biol Chem 287.

[24] Abrahamson, M., Dalboge, H., Olafsson, I., Carlsen, S., and Grubb, A. (1988) Efficient Production of Native, Biologically-Active Human Cystatin-C by Escherichia-Coli, Febs Lett 236, 14-18.

[25] Dalboge, H., Jensen, E. B., Tottrup, H., Grubb, A., Abrahamson, M., Olafsson, I., and Carlsen, S. (1989) High-Level Expression of Active Human Cystatin-C in Escherichia-Coli, Gene 79, 325-332.

[26] Hayashi, M., Iwamoto, S., Sato, S., Sudo, S., Takagi, M., Sakai, H., and Hayakawa, T. (2013) Efficient production of recombinant cystatin $\mathrm{C}$ using a peptide-tag, 4 AaCter, that facilitates formation of insoluble protein inclusion bodies in Escherichia coli, Protein Expres Purif 88, 230-234.

[27] Zhang, Q., Zhao, X. Z., Xu, X. Y., Tang, B., Zha, Z. L., Zhang, M. X., Yao, D. W., Chen, X. X., Wu, X. H., Cao, L., and Guo, H. Q. (2014) Expression and purification of soluble human cystatin $C$ in Escherichia coli with maltose-binding protein as a soluble partner, Protein Expres Purif 104, 1419.

[28] Zhou, Y. J., Zhou, Y., Li, J., Chen, J., Yao, Y. Q., Yu, L., Peng, D. S., Wang, M. R., Su, D., He, Y., and Gou, L. T. (2015) Efficient expression, purification and characterization of native human cystatin $C$ in Escherichia coli periplasm, Protein Expres Purif 111, 18-22.

[29] Files, D., Ogawa, M., Scaman, C. H., and Baldwin, S. A. (2001) A Pichia pastoris fermentation process for producing high-levels of recombinant human cystatin-C, Enzyme Microb Tech 29, 335-340.

[30] Li, Y. M., Li, D. J., Xu, X. J., Cui, M., Zhen, H. H., and Wang, Q. (2014) Effect of codon optimization on expression levels of human cystatin C in Pichia pastoris, Genet Mol Res 13, 4990-5000.

[31] Lindahl, P., Abrahamson, M., and Bjork, I. (1992) Interaction of Recombinant Human Cystatin-C with the Cysteine Proteinases Papain and Actinidin, Biochem J 281, 49-55.

[32] Krupa, J. C., and Mort, J. S. (2000) Optimization of detergents for the assay of cathepsins B, L, S, and K, Anal Biochem 283, 99-103.

[33] Illy, C., Quraishi, O., Wang, J., Purisima, E., Vernet, T., and Mort, J. S. (1997) Role of the occluding loop in cathepsin B activity, J Biol Chem 272, 1197-1202.

[34] Kuzmic, P., Elrod, K. C., Cregar, L. M., Sideris, S., Rai, R., and Janc, J. W. (2000) High-throughput screening of enzyme inhibitors: Simultaneous determination of tight-binding inhibition constants and enzyme concentration, Anal Biochem 286, 45-50.

[35] Williams, J. W., Morrison, J. F., and Duggleby, R. G. (1979) Tight-Binding Inhibitors as PseudoSubstrates of Dihydrofolate-Reductase, $P$ Aust Biochem Soc 12, 3-3.

[36] Pallitto, M. M., and Murphy, R. M. (2001) A mathematical model of the kinetics of beta-amyloid fibril growth from the denatured state, Biophys J 81, 1805-1822. 
[37] Berti, P. J., Ekiel, I., Lindahl, P., Abrahamson, M., and Storer, A. C. (1997) Affinity purification and elimination of methionine oxidation in recombinant human cystatin C, Protein Expres Purif 11, 111-118.

[38] Stadtman, E. R. (2004) Role of oxidant species in aging, Curr Med Chem 11, 1105-1112.

[39] Ekiel, I., Abrahamson, M., Fulton, D. B., Lindahl, P., Storer, A. C., Levadoux, W., Lafrance, M., Labelle, S., Pomerleau, Y., Groleau, D., LeSauteur, L., and Gehring, K. (1997) NMR structural studies of human cystatin $\mathrm{C}$ dimers and monomers, $\mathrm{J}$ Mol Biol 271, 266-277.

[40] Jankowska, E., Wiczk, W., and Grzonka, Z. (2004) Thermal and guanidine hydrochloride-induced denaturation of human cystatin C, Eur Biophys J Biophy 33, 454-461.

[41] Rzychon, M., Chmiel, D., and Stec-Niemczyk, J. (2004) Modes of inhibition of cysteine proteases, Acta Biochim Pol 51, 861-873.

[42] Ekiel, I., and Abrahamson, M. (1996) Folding-related dimerization of human cystatin C, J Biol Chem 271, 1314-1321.

[43] Abrahamson, M., Mason, R. W., Hansson, H., Buttle, D. J., Grubb, A., and Ohlsson, K. (1991) Human Cystatin-C - Role of the N-Terminal Segment in the Inhibition of Human Cysteine Proteinases and in Its Inactivation by Leukocyte Elastase, Biochem J 273, 621-626.

[44] Royer, C. A. (2006) Probing protein folding and conformational transitions with fluorescence, Chem Rev 106, 1769-1784.

[45] Juszczyk, P., Paraschiv, G., Szymanska, A., Kolodziejczyk, A. S., Rodziewicz-Motowidlo, S., Grzonka, Z., and Przybylski, M. (2009) Binding Epitopes and Interaction Structure of the Neuroprotective Protease Inhibitor Cystatin C with beta-Amyloid Revealed by Proteolytic Excision Mass Spectrometry and Molecular Docking Simulation, J Med Chem 52, 2420-2428.

[46] Aldred, A. R., Brack, C. M., and Schreiber, G. (1995) The Cerebral Expression of Plasma-Protein Genes in Different Species, Comp Biochem Phys B 111, 1-15.

[47] Wahlbom, M., Wang, X., Lindstrom, V., Carlemalm, E., Jaskolski, M., and Grubb, A. (2007) Fibrillogenic oligomers of human cystatin $\mathrm{C}$ are formed by propagated domain swapping, $J$ Biol Chem 282, 18318-18326. 


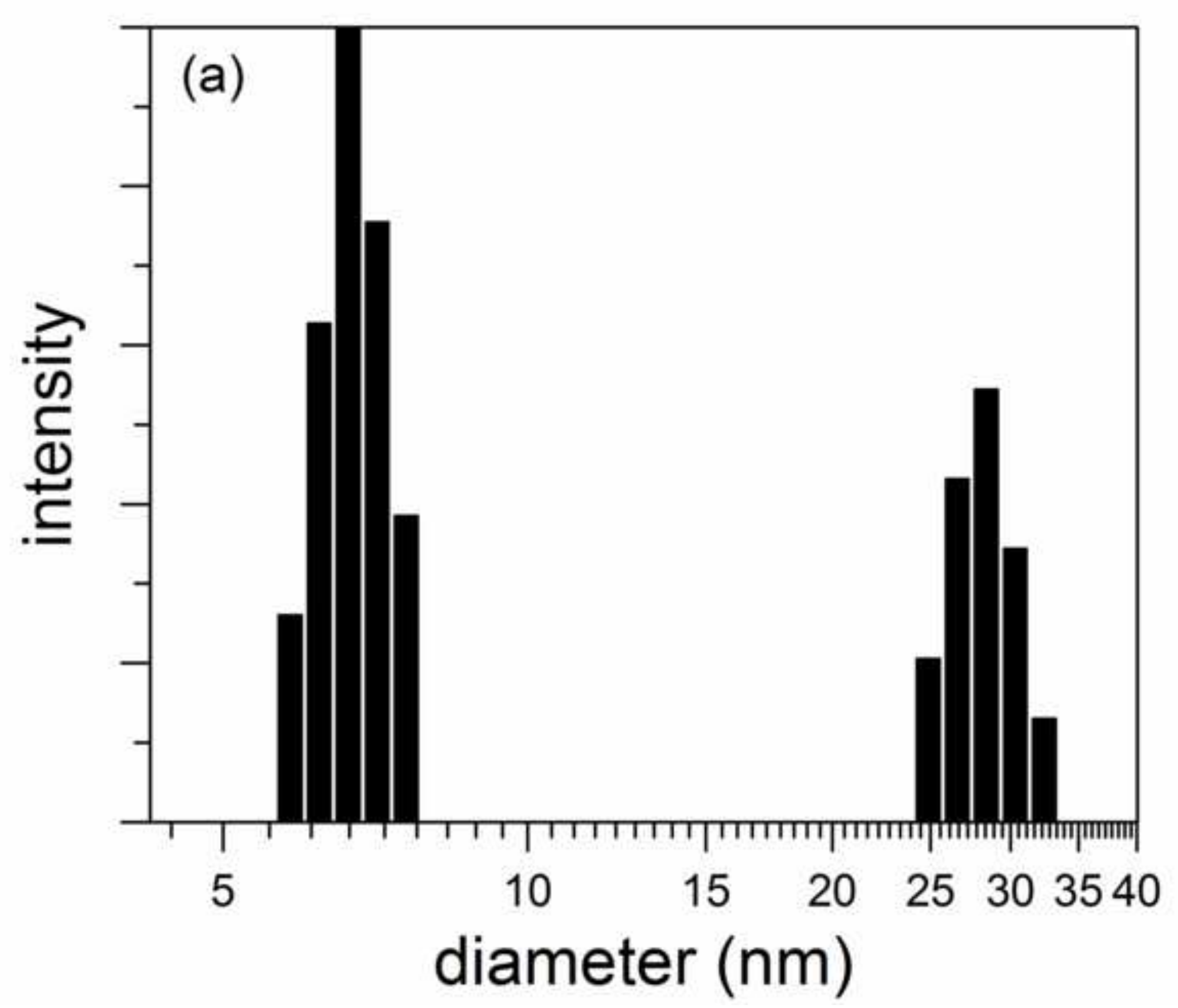




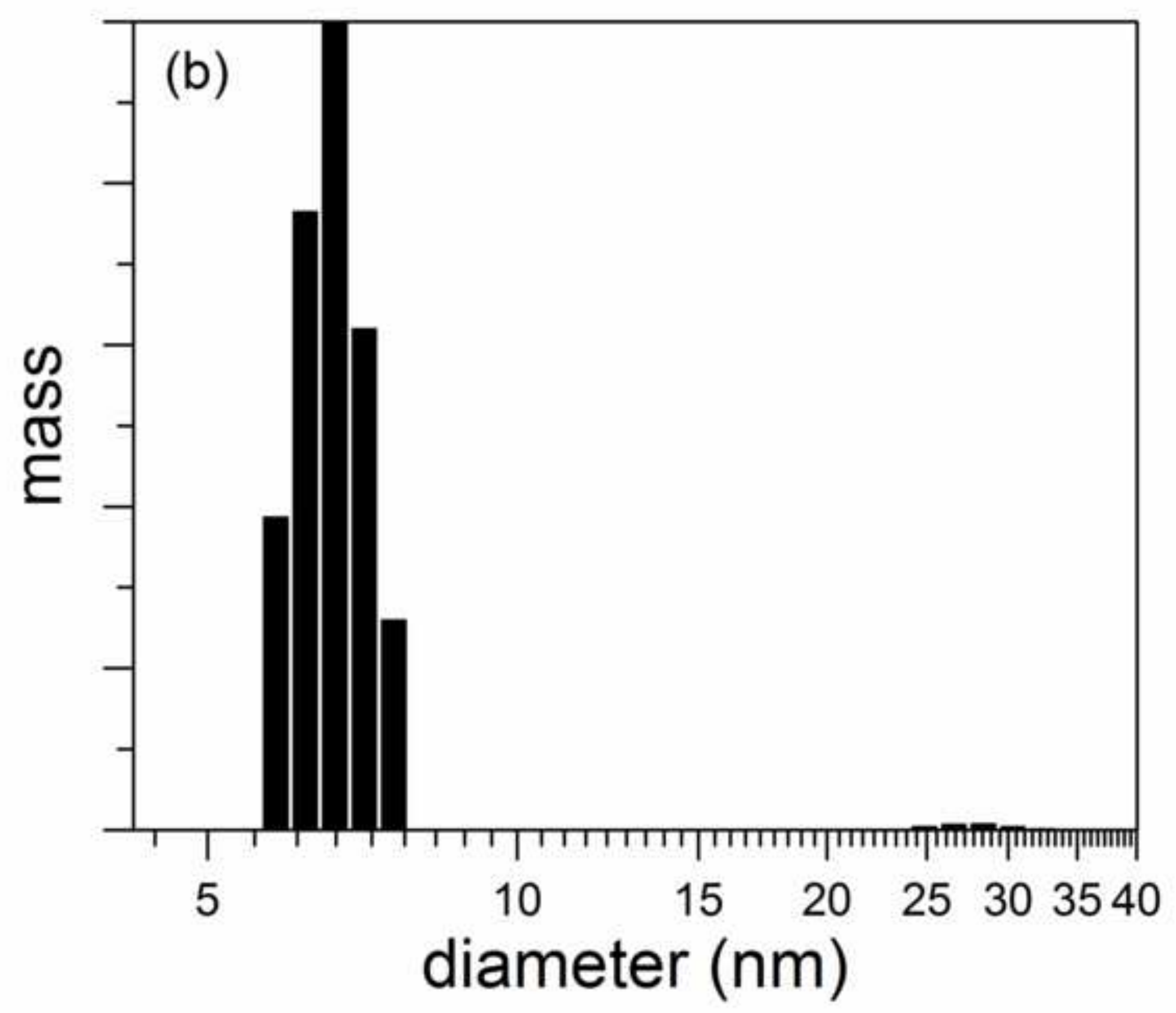



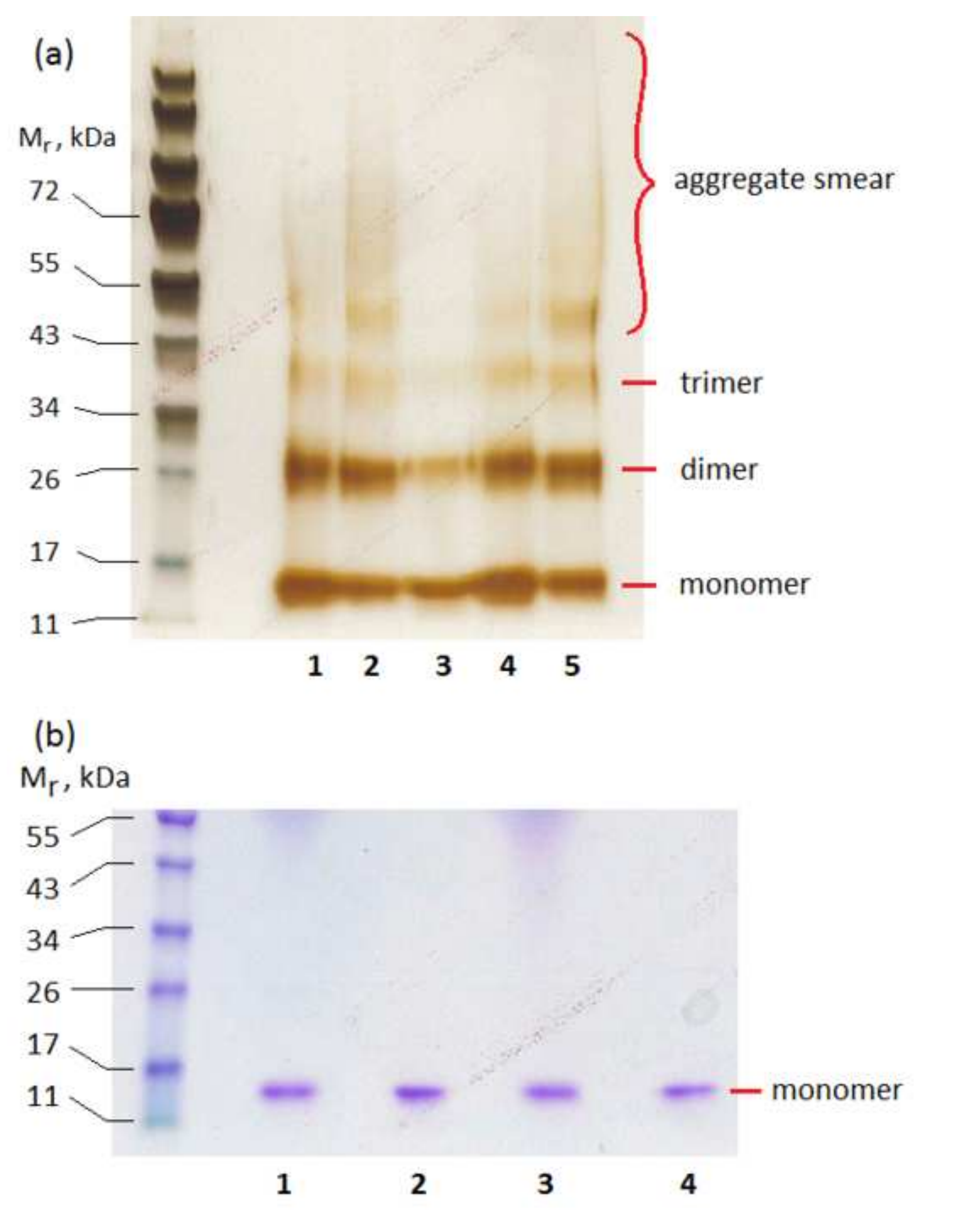


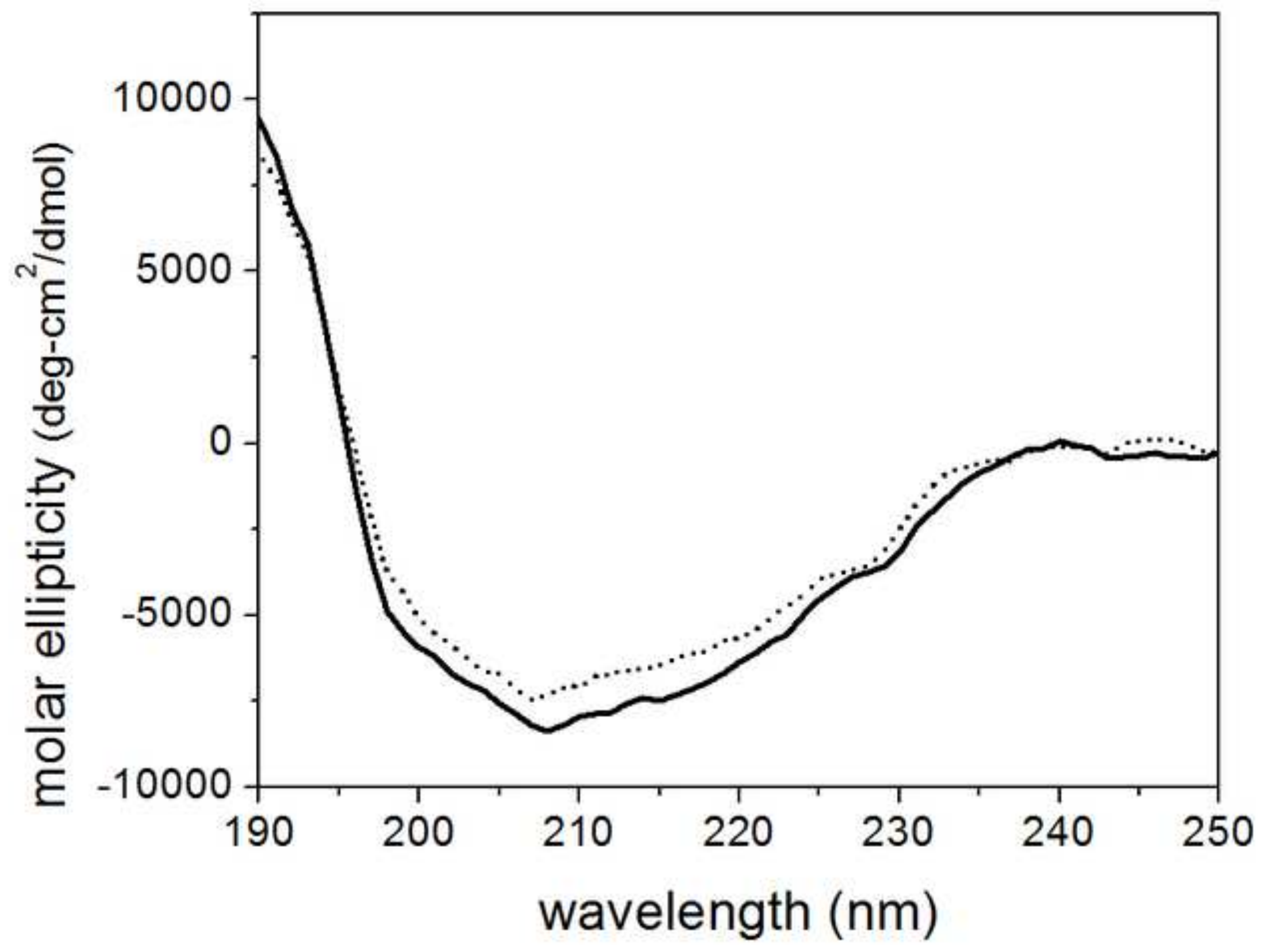




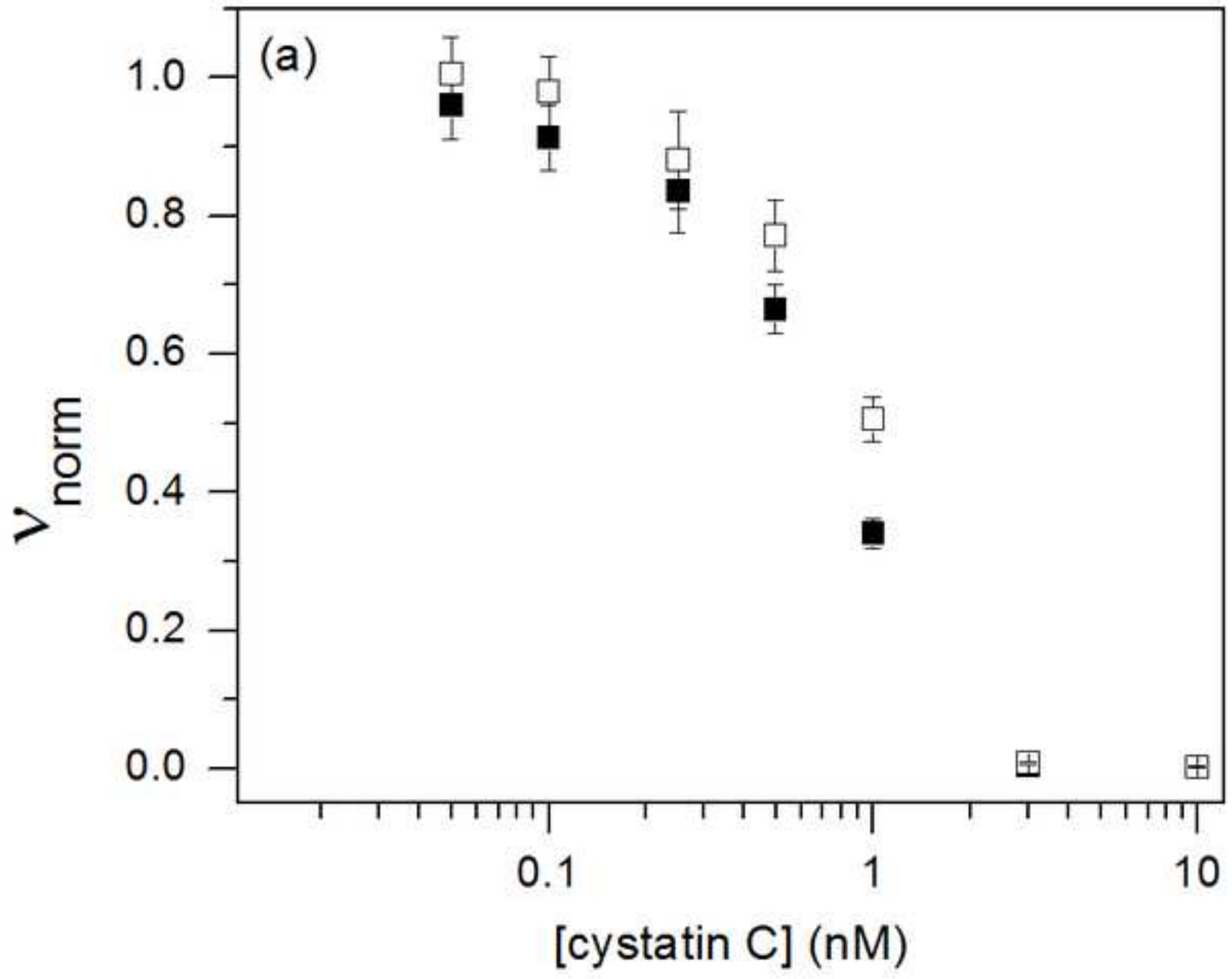




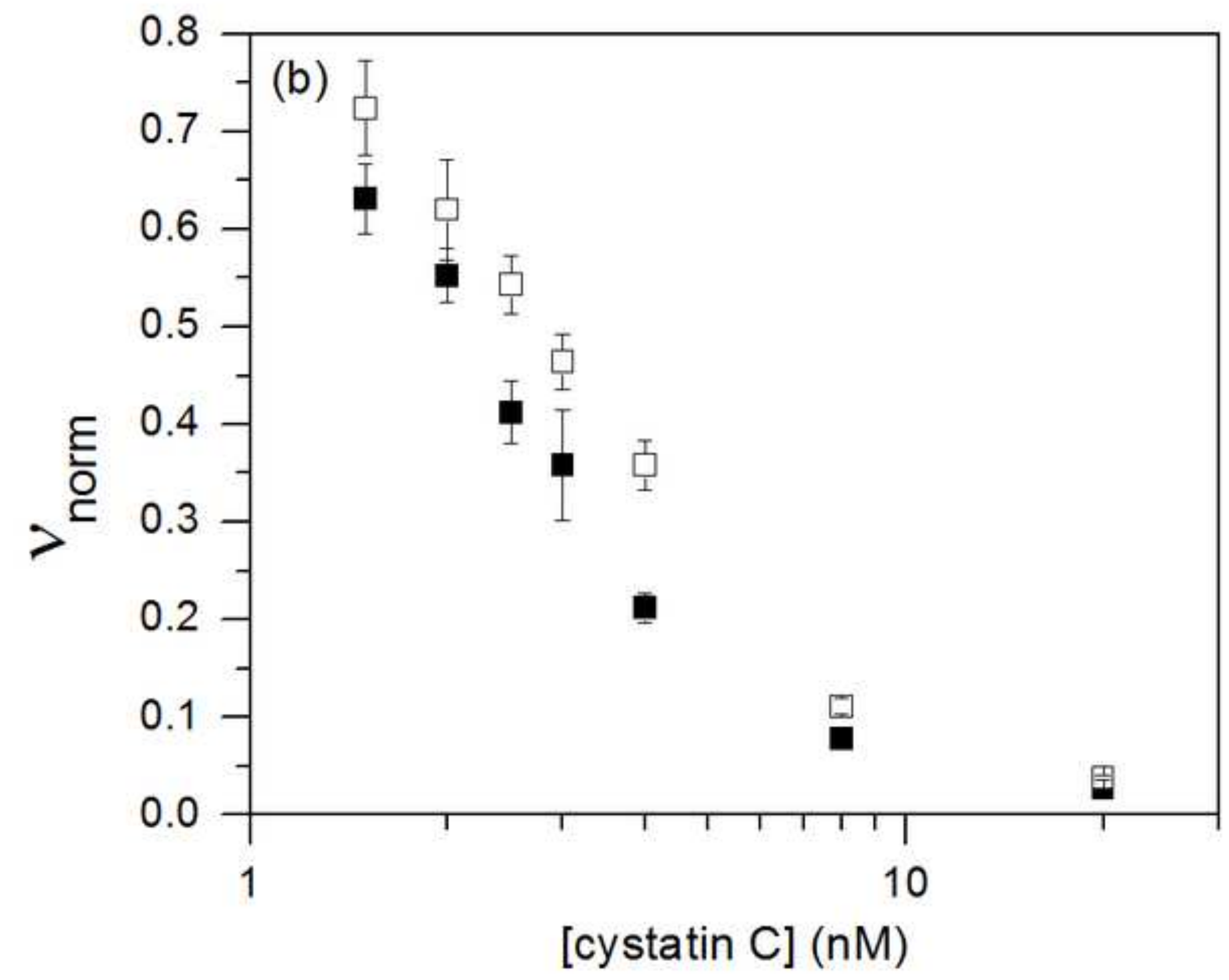

[cystatin C] (nM) 


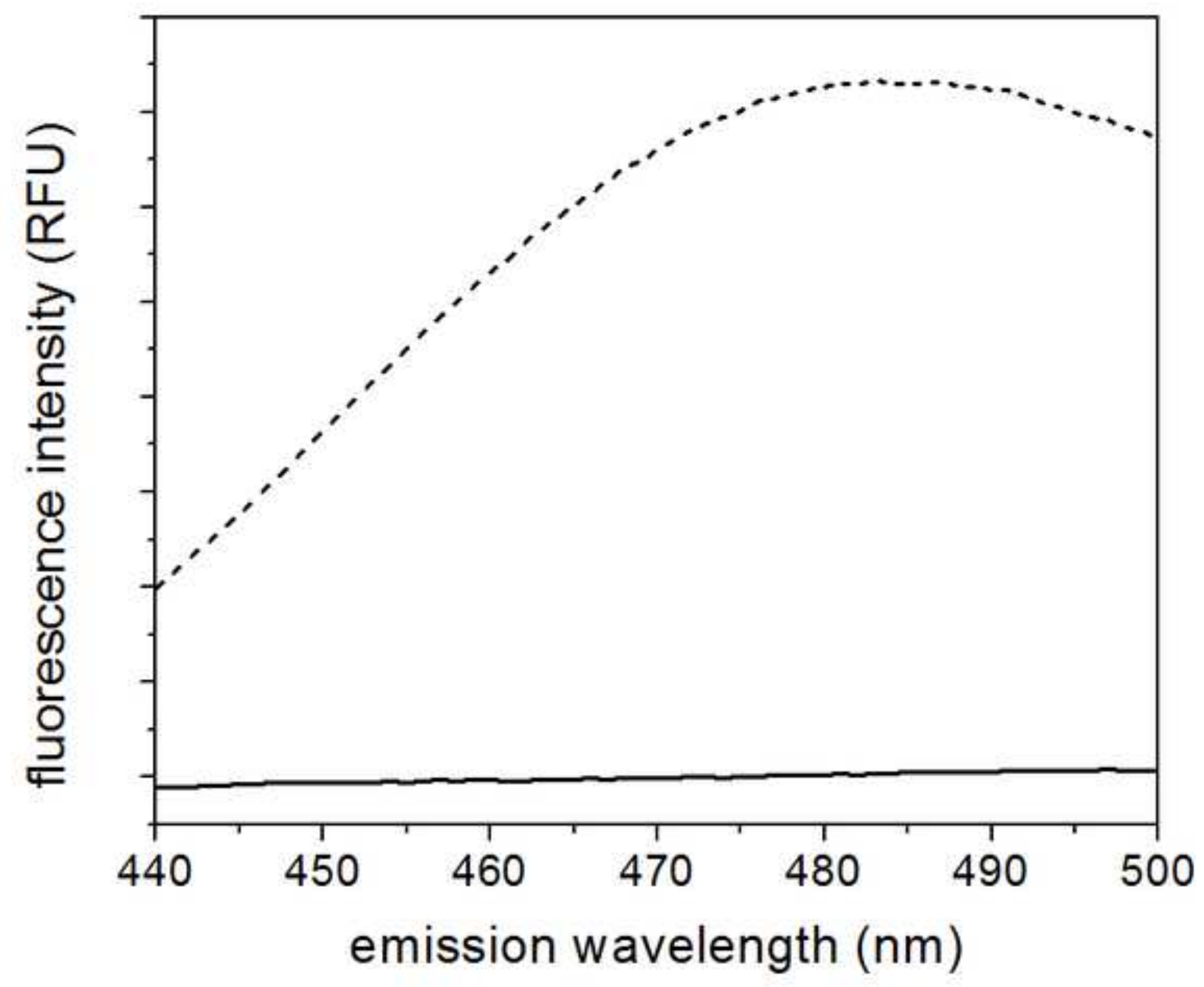




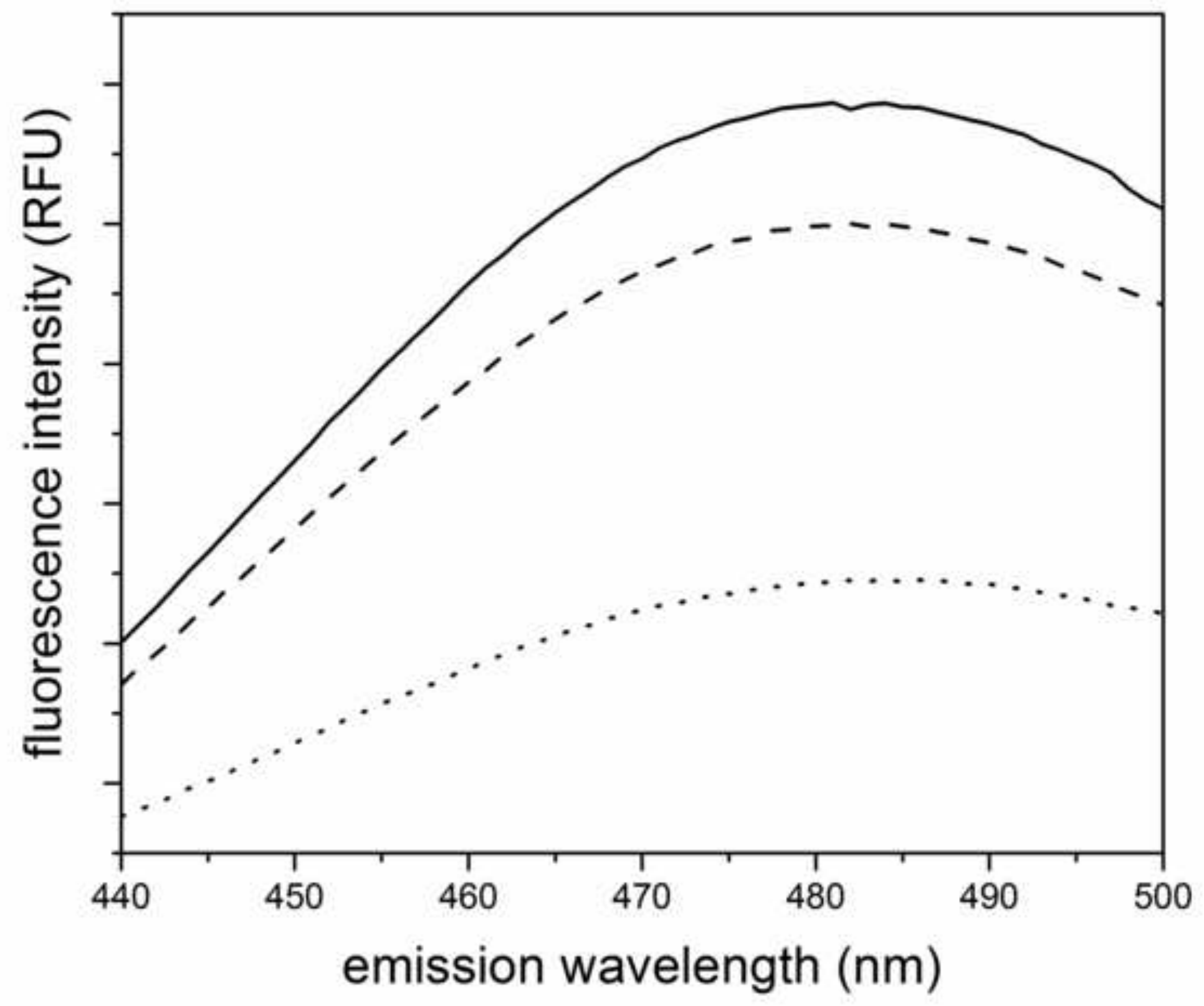




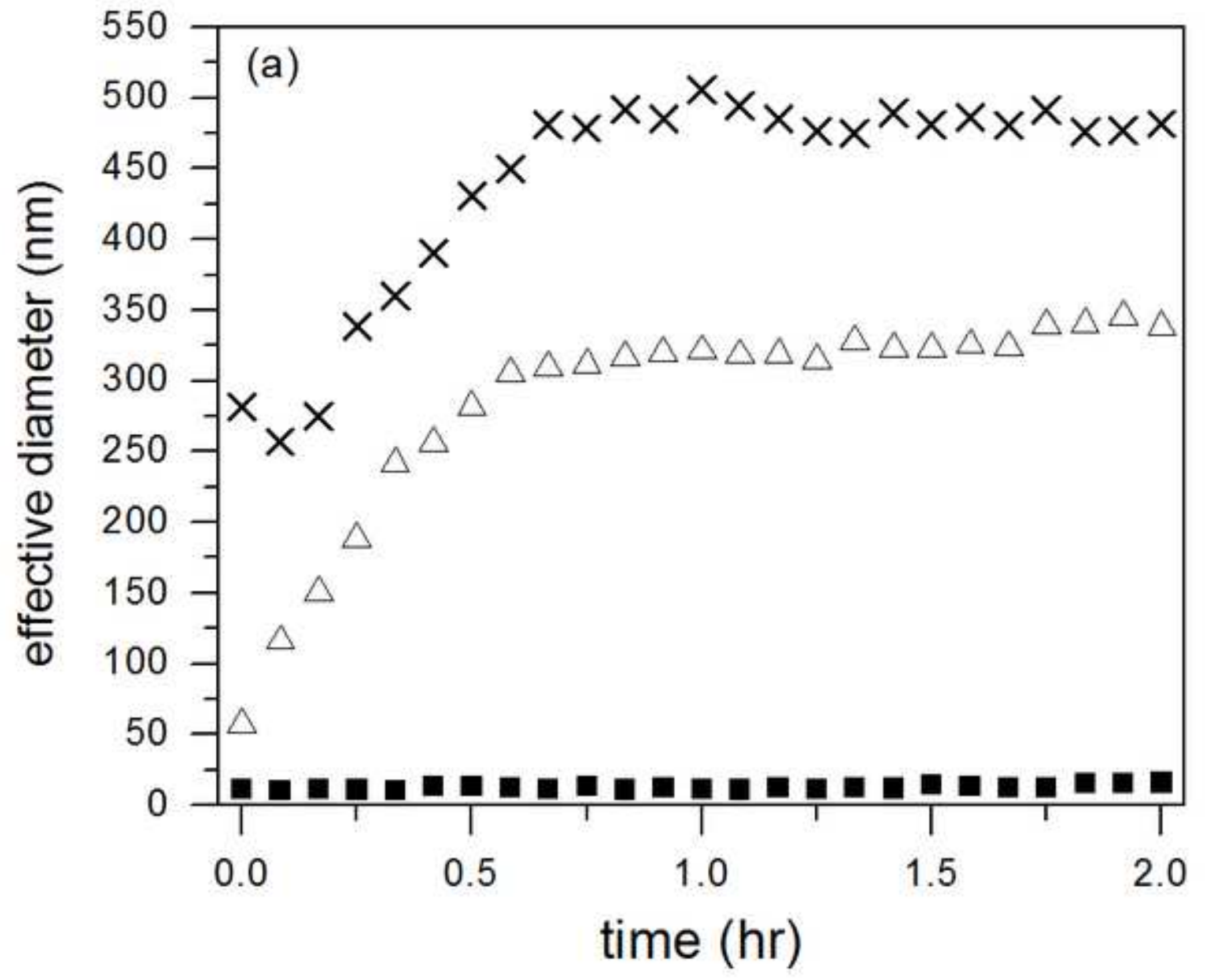




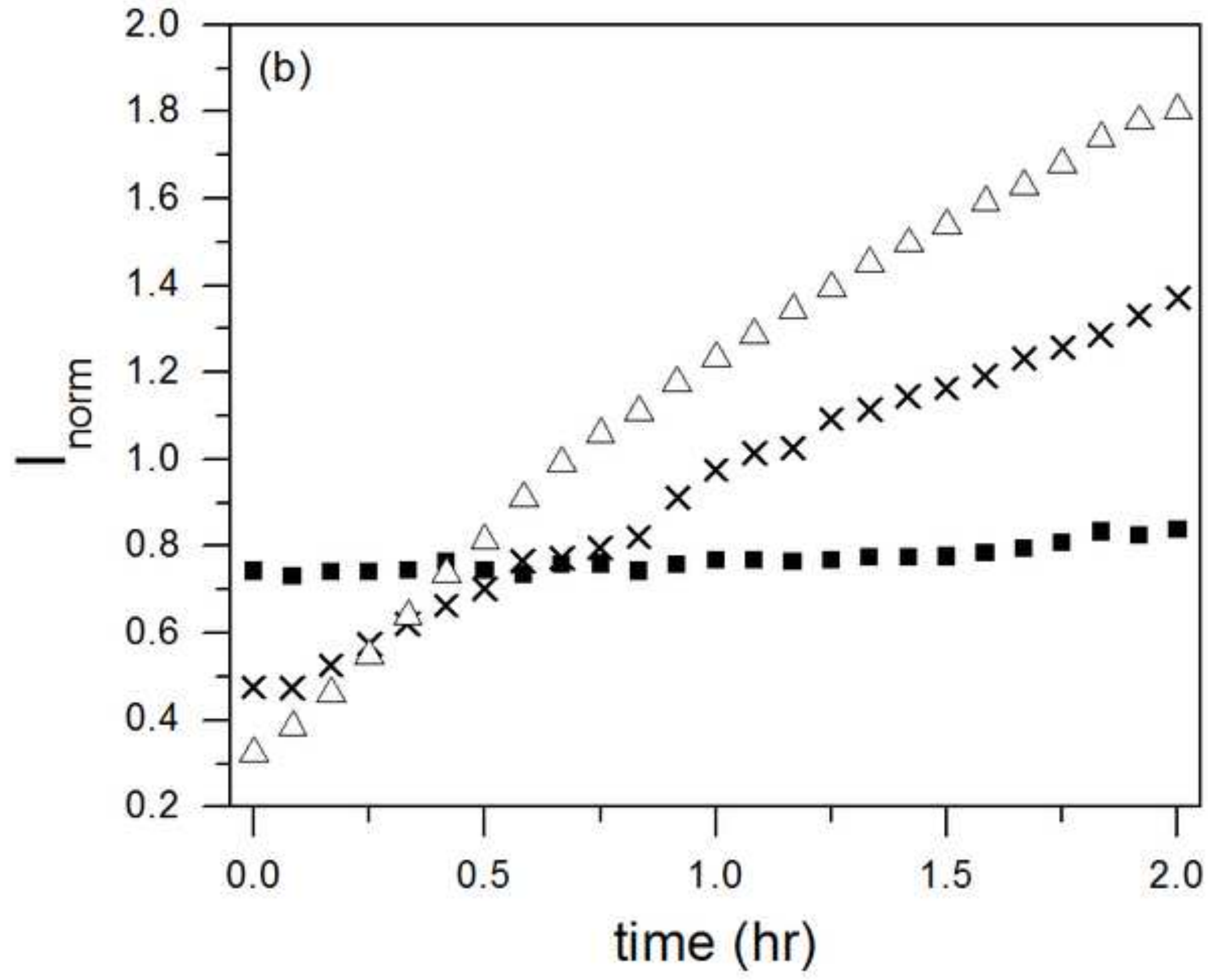

